\section{EOSINOPHILS IN THE SPUTUM}

BY

\section{JOHN VAUGHN, M.D.}

(From the Department of Pathology, Mount Sinai Hospital. Chicago; lately of the East African Medical Survey and Filariasis Research, Mwanza, Tanganyika)

The presence of eosinophil leucocytes in the sputum has been traditionally associated with bronchial asthma. Early writers regarded this finding as diagnostic (Bezançon and Israëls de Jong, 1912; Barth, 1921), but nowadays it has a wider significance, being found in chronic bronchitis, whooping-cough, carcinoma of the lung, etc. (Unger, 1945). The sputum eosinophilia of asthmatics was in some measure accounted for when Marchand (1915) found, in necropsies on asthmatic patients, extensive infiltration of the respiratory mucosa by eosinophil leucocytes. This is now an accepted pathological finding, as is also the infiltration by eosinophils of the nasal mucosa and sinus epithelium in other allergic states (Cooke, 1947 ; Baxter and Rose, 1953). Of the eosinophils in the respiratory mucosa, some were mononuclear cells, and there were many surrounding granules of an eosinophilic character; this appearance led Bezançon and Bernard (1930), Cooke (1932), and others to deduce that the eosinophils had been formed locally in response to an antigen-antibody reaction-the accepted mechanism of allergic bronchial asthma. Earlier, however, Huber and Koessler (1922) had recognized these mononuclear cells and scattered granules as stages in the degeneration of the eosinophil and had maintained the identity of the eosinophil in the lungs with the eosinophil circulating in the blood. Several attempts have been made to relate, numerically, the eosinophils in the blood with those in tissues and fluid discharges, but without much success (Cooke, 1932; Knott and Pearson, 1934 ; Cowie and Jimenez, 1936).

Eosinophilic infiltration of the pulmonary tissues was recently described in guinea-pigs which had developed eosinophilia following injections of toxic materials (Vaughn, 1953). In these experiments it was found that the eosinophils first increased in the circulating blood, then appeared in the lungs, and finally were found within the respiratory passages. From the chronological sequence it was suggested that the eosinophil leucocyte, formed in the bone marrow, proceeds by way of the blood stream to the lungs, migrates into the pulmonary tissues, whence it passes into the bronchioles and bronchi, and so is discharged from the body.

While working among the natives of Sukumaland, in Tanganyika, it was noticed that many specimens of sputum contained eosinophil leucocytes. The relationship which this finding might bear to the high incidence in the local population of parasitic disease, and, of course, to the eosinophilia of the blood so often an accompaniment to it, was considered and an attempt made to assess this relationship. Consequently the simultaneous examination of blood and sputa from a group of the local African natives was undertaken.

\section{Methods and Results}

African natives attending the out-patient department of Mwanza Hospital comprised the test group. These patients were not selected in any way except that in view of the difficulty of obtaining specimens of sputum from young children such cases were omitted. There were only 10 cases of clinically apparent respiratory disorder in the whole series.

Patients were invited to expectorate into a Petri dish and smears were made of suitable specimens. Those specimens which consisted only of saliva were rejected and the patient was encouraged to try again. The smears were fixed, while still wet, in Schaudinn's fluid and were subsequently stained by haematoxylin and eosin, two such smears from each patient being examined. Differential leucocyte counts were found to be unsatisfactory owing to the uneven, often focal, distribution of the eosinophils. It was felt that a general impression of the contents of the smears as a whole would be of more value, and thus the smears have been reported as containing no eosinophils, scanty eosinophils, small numbers, or moderate to large numbers of eosinophils. Eosinophil counts of the peripheral blood were carried out by the method of Thorn et al. (1948).

In all, 205 Africans were examined in this way, and by a simple coding procedure examinations of the blood and sputum were made in complete independence.

In the Table the frequency and density of eosinophils in the sputum are shown in the various groups of Africans examined, the patients being arranged according to the level of eosinophils in the peripheral blood.

Occurrence and Intensity of Sputum Eosinophilia in 205 Africans with Various Levels of Eosinophil Leucocytes in the Peripheral Blood

\begin{tabular}{|c|c|c|c|}
\hline \multirow{2}{*}{$\begin{array}{l}\text { Eosinophils in Sputum } \\
\end{array}$} & \multicolumn{3}{|c|}{ Eosinophils in Peripheral Blood } \\
\hline & 0-500/c.mm. & 501-1,000/c.mm. & Over 1,000 'c.mm \\
\hline $\begin{array}{llr}\text { None } . . & . & . \\
\text { Scanty } & \ldots & . \\
\text { Small } & \text { No. } \\
\text { Moderate to large } & \text { No. }\end{array}$ & $\begin{array}{r}40 \\
18 \\
12 \\
3\end{array}$ & $\begin{array}{l}14 \\
21 \\
28 \\
12\end{array}$ & $\begin{array}{r}6 \\
3 \\
26 \\
22\end{array}$ \\
\hline No. of patients & 73 & 75 & 57 \\
\hline
\end{tabular}

\section{Discussion}

Of the patients examined, nearly two-thirds had an eosinophilia of 500 or more eosinophil leucocytes per c.mm. of blood, and the general pattern seems to be that as the degree of eosinophilia increases so does the frequency and density of the eosinophilia of the sputum. About one-fourth of the cases, however, do not follow this trend, some eosinophilic patients showing no sputum eosinophilia and some noneosinophilic patients having numerous eosinophils in the sputum. To assess the importance of these dissenting results, attention must first be drawn to the technical inaccuracies in estimating the frequency of eosinophils in the smears. Also, in the animal experiments quoted above, eosinophilia of the blood was not synchronous with the appearance of these cells in the bronchioles, there being a time lag of some hours. This time lag was also evident as the eosinophilia subsided. This asynchronism has been observed in asthmatics. Tuft (1949) remarks that eosinophils in the sputum "are especially abundant towards the end of the attack." Generally, however, the trend of the present findings does support the view that eosinophils appear in the sputum, and of course in the tissues of the lungs, as late stages in the course of an eosinophilia.

The failure of former workers to establish such a correlation probably lies in their having investigated cases of allergy, the antigenic stimulus of which may not have been enough to produce an eosinophilia of sufficient intensity or duration to permit the relationship to be observed. In the present study the eosinophilia in almost all cases was a response to parasitic infestation, and it is among such cases that some of the highest eosinophil counts have been encountered (Wintrobe, 1951). In one of the cases included here there was a peak eosinophil count of 18.800 cells per c.mm., and the eosinophilia persisted for 10 days. 
In a highly parasitized community such as that here examined, the frequency of eosinophilia, including pulmonary eosinophilia as revealed by the sputum, is not a new finding, for there have been many reports associating eosinophilic infiltration of the lungs with parasitic disease (Söderling, 1939; Wintrobe, 1951). The infiltration syndrome (Loeffler, 1932) should thus be expected in any condition in which there is a substantial increase in the number of circulating eosinophil leucocytes for any length of time-for example, periarteritis nodosa (Middleton and Carter, cited by Tisell, 1941).

As evidence accumulates there seems to be less doubt that the state of eosinophilia, of whatever primary aetiology, embodies an increase in the number of eosinophil leucocytes circulating in the blood, their subsequent migration (? selective segregation) into the tissues of the lungs, and their eventual discharge into the respiratory passages and so out of the body.

\section{Summary}

Simultaneous examination of blood and sputum for eosinophils was made in 205 African natives in an area where the incidence of parasitic infestation is high.

The results obtained suggest that there is some association between eosinophilia of the blood and that of the sputum.

This association is discussed in relation to the reports of pulmonary eosinophilic infiltration complicating parasitic disease.

It is suggested that eosinophilia of the sputum and its preceding eosinophilic infiltration of the lungs are integral parts of a general eosinophilia, and that the demonstration of eosinophils in sputum indicates that an eosinophilia is or has recently been in progress.

\section{REFERENCES}

Barth, H. (1921). Semiologie de l'apparell respiratoire, p. 28. Paris Baxter, J. D., and Rose, B. (1953). J. Allergy, 24. 18.

Bezancon, F., and Bernard, E. (1930). Ann. Med., 27, 204.

and Israèls de Jong, S. (1912). Traité de l'examen des crachats, p. 81 Paris.

Cooke, R. A (1932). Amer. J. med. Sct., 183, 309

(1947). Allergy in Theory and Practice, $\mathrm{p}$. 139. Saunders, Philadelphia.

Cowie, D. M., and Jimencz, B. (1936). Arch. intern. Med.. 57, 85.

Cowie, D. M., and Jimencz, B. (1936). Arch. intern. Med.,

Knott, F. A., and Pearson, R. S. B. (1934). Guy's Hosp. Rep. 84, 230

Rnott, F. A., and Pearson, R. S. B. (1934). Guy's

Loeffier, W. (1932). Beitr. Klin. Tuberk., 79, 365.

Söderling, B. (1939). Arch. Dis. Childh. 14, 22.

Söderling, B. (1939). Arch. Dis. Childh., 14, 22. J. Amer med Ass, 137, 1005 .

Tisell, F. (1941). Acta med. scand., Suppl. . 123, 284.

Tisell, F. (1941). Acta med. scand., Suppl., 123, 284 .

Tuft, L. (1949). Clinical Allergy, 2nd ed, p. 342. Kimpton, London

Unger, L. (1945). Bronchial A

Wintrobe, M. M. (1951). Clinical Haematology, 3rd ed., pp. 215, 217 Kimpton, London.

The annual report of the National Institute for the Blind draws attention to the manifold activities now being undertaken by that organization. Of particular interest is the development of the new solid-dot Braille, which composes dots of plastic ink on paper instead of impressing them, and which will make possible the much cheaper production of books, periodicals, music, etc., for the blind. Moon type is a useful complement to Braille, especially for those who become blind in old age. It was developed by Dr. William Moon (1818-94), who lost the sight of one eye at the age of 4 , following an attack of scarlet fever, and became totally blind at the age of 22. Although Moon literature is costly to produce, the Institute has continued to supply it. Nearly 50,000 volumes of literature and 2,000 volumes of music were among the year's output of the Institute during the year. The physiotherapy school continues to make its useful contribution to medicine ; an arrangement made with the Whittington Hospital, Highgate, has enabled skilled physiotherapy students of the Institute to give 4,000 treatments a month to out-patients. The Institute has begun a new policy whereby its members may obtain Braille watches, clocks, literature, and other goods at greatly reduced cost.

\section{Medical Memoranda}

\section{Prevention of Post-operative Backache in Women}

Some women suffer from low backache following prolonged abdominal or vaginal operations. The pains are sometimes so excruciating after awakening from the anaesthetic (and commonly during the first post-operative day) that only morphine brings relief. Some of these patients say that they suffered more from the backache than from the effects of actual operation, and this backache may persist for months after the operation.

This kind of backache is due to the forcible flattening of the lumbar spine curvature while the deeply anaesthetized patient is stretched out on a flat operating table. During vaginal operations in the extreme lithotomy position this flattening of the curvature is aggravated by extreme flexion of the thighs. The pains are caused partly by pulling on the interlumbar and sacro-lumbar ligaments, which sometimes leads to slight dislocation of the intervertebral joints.

In other patients, predisposed to degenerative changes in the intervertebral disks, the widening of the lumbar bodies by the forcible flattening of the curvature leads to some protrusion of a disk or disks, with resultant pressure on the dura mater, causing pains similar to those of the common disk lesions. Cyriax calls this kind of pain " dural pains." Deep anaesthesia leads to relaxing of the lumbar muscles, which facilitates the flattening of the curvature. Since the introduction of the relaxing curare preparations the evidence tends to suggest that this kind of backache has become commoner.

In women operated on in the lithotomy position another factor may add to this flattening of the lumbar curvature. If, after the operation, the legs are not put gently into the normal position, but instead one leg is first stretched while the other is still fixed to the stirrup, undue force is applied to the sacro-iliac joints, causing strain to the ligaments and resulting in mild dislocation of these joints.

The flattening is still further increased by the routine nursing with pillows arranged in such a way that the lumbar region remains unsupported. Nurses have for years been trained to adjust the pillows in this manner; four to six pillows are usually placed under the shoulders and back to keep the patient in a propped-up position, but no attention is paid to the fact that the lumbar region is left entirely unsupported. One can push a hand underneath, as if in a tunnel. Consequently the already flattened curvature resulting from lying on the operating table is still unsupported, and so the back pains are increased.

A fourth contributory factor is a mattress which is too soft in texture; this gives too easily, causing dents and so contributes to the flattening.

Two types of women are prone to such post-operative backache-the very stout and the asthenic flabby type. In the former the lumbar muscles are permanently strained in balancing the heavy abdominal weight. These women always have an increase of the lumbar curvature, and during the operation the already overtired lumbar muscles readily give way. The second type have muscles and ligaments constitutionally weak. The intervertebral ligaments are very loose and the spine curvature relaxes easily.

These unpleasant backaches can be prevented by a very simple procedure : (1) During the operation a cushion, not too soft, should always be placed under the lumbar curvature to prevent flattening of that part of the spine. (2) When the patient is changed from the lithotomy to the normal position both legs should be stretched gently at the same time. (3) Nurses should be taught never to-allow the lumbar region to be unsupported while the patient is lying on her back, and especially during the first few days after the operation. An ordinary and not too soft pillow 